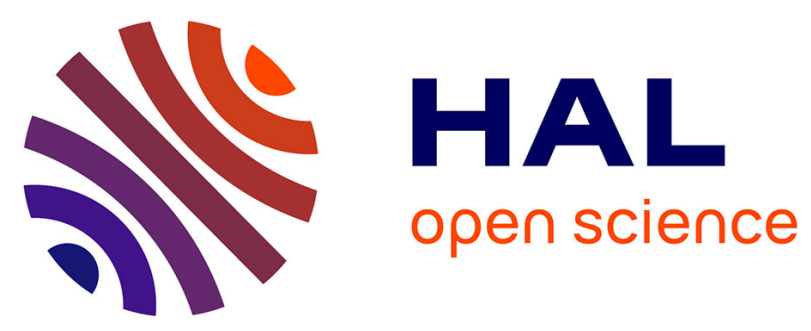

\title{
Numerical analyses of the sound transmission at low frequencies of a calibrated Insulating Glazing Unit
} Chaïma Soussi, Mathieu Aucejo, Walid Larbi, Jean-François Deü

\section{To cite this version:}

Chaïma Soussi, Mathieu Aucejo, Walid Larbi, Jean-François Deü. Numerical analyses of the sound transmission at low frequencies of a calibrated Insulating Glazing Unit. Applied Acoustics, 2021, 179, pp.108065. 10.1016/j.apacoust.2021.108065 . hal-03200124

\section{HAL Id: hal-03200124 \\ https://hal.science/hal-03200124}

Submitted on 16 Apr 2021

HAL is a multi-disciplinary open access archive for the deposit and dissemination of scientific research documents, whether they are published or not. The documents may come from teaching and research institutions in France or abroad, or from public or private research centers.
L'archive ouverte pluridisciplinaire HAL, est destinée au dépôt et à la diffusion de documents scientifiques de niveau recherche, publiés ou non, émanant des établissements d'enseignement et de recherche français ou étrangers, des laboratoires publics ou privés. 


\title{
Numerical analyses of the sound transmission at low frequencies of a calibrated Insulating Glazing Unit
}

\author{
Chaima SOUSSI ${ }^{\mathrm{a}}$, Mathieu AUCEJO*a, Walid LARBI ${ }^{\mathrm{a}}$, Jean-François \\ DEÜ \\ ${ }^{a}$ Laboratoire de Mécanique des Structures et des Systèmes Couplés, \\ Conservatoire National des Arts et Métiers, \\ 2 rue Conté, 75003 Paris, France.
}

\begin{abstract}
The acoustic performances of building elements such as windows are carried out in laboratory according to standards. In addition to the high cost of the experimental tests, the measurements at low frequencies face some difficulties such as the lack of reproducibility, the rooms' modal behaviour effect and the diffuseness of the acoustic field. To separately study each source of deviation from the ideal experimental situation, four numerical configurations, based on experimental conditions, are proposed to characterize the transmission loss (TL) of an Insulation Glazing Unit (IGU) below $500 \mathrm{~Hz}$. The effect of the emitting and receiving rooms with a comparison to the ideal configuration which has a free field on both sides of the IGU are investigated. The numerical model used for the IGU is calibrated from an Experimental Modal Analysis. As expected, TL results show that there is a significant effect of the modal behavior and the acoustic properties of the rooms at low frequencies. Numerical results are compared to those obtained from experimental tests and a good agreement in the all frequency range of interest is observed. In addition, parametric studies are carried out to investigate the influence of the variation of some properties of the studied structure such as the structural damping and the panel's thickness.
\end{abstract}

Keywords: Insulating Double Glazing, Transmission Loss, Experimental Modal Analysis, Numerical modeling.

\footnotetext{
${ }^{*}$ Corresponding author. E-mail address: mathieu.aucejo@lecnam.net
} 


\section{Introduction}

This research work concerns the vibro-acoustic response of a full scale domestic wooden windows at low frequencies. Since windows are mainly mounted in the exterior building facades, the present study is more particularly focused on the transmission of outdoor airborne noises which are generally emitted from the traffic corresponding to low-pitched noise [1]. Due to the complexity of the structure, existing works only consider the simpler part of the system namely the Insulting Glass Unit (IGU).

The sound insulation of double partition units, like double panels, has been widely studied. The earlier analytic predictive models were developed by Beranek and Work [2] and London [3] who studied the sound insulation of infinite plates excited with plane waves. Since then, many other models have been developed to describe various physical phenomena such as the influence of the non-resonant vibration modes and resonances of a cavity [4], the sound bridges between the two panels [5] and the absorption in the acoustic medium [6]. However, Hongisto [7] showed with a detailed study on seventeen models of double panels that there is a significant variation between them, which car reach $20 \mathrm{~dB}$, and no single model was able to well predict the sound performance of such systems.

Practically, the sound insulation of a building element is based on its sound transmission loss (TL). The latter indicator is determined with experimental tests according to standards [8]. The tests are carried out in an acoustic laboratory using two finite-sized rooms and one or many loudspeakers to create the sound field excitation with the assumption that the flanking transmission is neglected. The standards assume that the sound field in the two rooms is perfectly diffuse which means that the energy density is the same on all points of the volume [9]. However, no diffuse field condition can be expected below the Schroeder frequency [10], since at low frequency range, the few rooms modes lead to standing waves which dominate the acoustic field. Utley [11] stated that the difference between the measured transmission loss and the mass low prediction depends on the characteristics of the rooms of the test laboratory rather than the intrinsic panel properties. Inter-comparisons of the transmission loss between ISO laboratories [12] and ASTM laboratories [13] evidenced that considerable differences up to $8 \mathrm{~dB}$ were found for frequencies below Schroeder frequency due to mounting conditions, frames and apertures. 
As reported by many authors $[6,14,15]$, at very low frequencies, theoretical and experimental approaches of the transmission loss through partition between rooms are highly dependent on the test conditions. In other words, it means that the predictive TL is valid only for the specific case under examination. To overcome this difficulty, numerical methods can be considered as a mean of introducing more representative measurement conditions to study the particularities of each case. In addition to the energetic approach such as Statistical Energy Analysis (SEA) or its improved version the Statistical modal Energy distribution Analysis (SmEdA), numerical methods such as the Boundary Element Method (BEM) and the Finite Element Method (FEM) are available to solve the problem of acoustic insulating. The choice of the adequate one depends on the computational cost and the frequency range of interest.

The SEA introduced in [16, 17] is based on the statistical energy exchanges of diverse subsystems. Due to the fact that underlying assumptions taken in this method which can be unrealistic in some cases, Maxit et Guyader [18] extended it to SmEdA in order to take into account the modal energy distribution. Despite these improvements, the energetic approaches are reliable only at high and medium frequency range with the view to the significant uncertainties due to the few resonant modes in each of the subdomains [19]. To this end, an hybrid approach was developped by Shorter and Langley [20] that combines the finite element method and statistical energy analysis in a single model. This method consists in modeling the deterministic components with the FEM while the statistical components are described in terms of their vibrational energy with SEA [20]. However, at low frequency range, due to the high modal behavior of the subdomains in the building sector, the FEM and BEM provide a more accurate prediction of the sound transmission loss. Santos et Tadeu [21] considered that the BEM approach could be a good tool to solve unbounded problems because it automatically satisfies the far field conditions. Sgard et al. [22] studied the transmission loss through double partition using the FEM for different layers of porous-elastic material coupled to a variational BEM to account for fluid excitation. Only the FEM has been employed by Maluski and Gibbs [23] to investigate the sound insulation of a wall mounted between two rooms and results pointed out a strong dependence between the TL and the modal behavior of both rooms and of the partition.

Despite the numerous existed studies which focused on the sound insulation, the dilemma of the sensibility of this acoustic indicator to its environ- 
ment at low frequencies is to the best of our knowledge still unsolved. That is why ISO 12999-1 standard [24] authorises deviations on TL.

\section{Materials and methods}

This section exposes the different steps of the proposed modeling strategy.

\subsection{Sound transmission loss}

Basically, the sound transmission loss characterizes the acoustic insulation of a structure and it is defined as:

$$
T L=10 \log _{10}\left(\frac{\Pi_{i n c}}{\Pi_{\text {rad }}}\right),
$$

where $\Pi_{i n c}$ and $\Pi_{\text {rad }}$ are the incident and the radiated sound power by the structure, respectively.

In experimental measurements, according to standard [8], the acoustic tests are carried out in a laboratory composed of two reverberant rooms separated by a common wall containing an opening in which the test element is mounted. The incident and transmitted sound power are determined indirectly by measuring the average sound pressure levels $L_{e}$ and $L_{r}$ in emitting and receiving room, respectively, and the sound transmission loss is determined as:

$$
T L=L_{e}-L_{r}+10 \log _{10} \frac{S}{A},
$$

where $S$ is the area of the test specimen and $A$ is the equivalent sound absorption area in the receiving room.

\subsection{Numerical configurations of the problem}

In the present paper, the Finite Element Method is used to better understand the rooms effect on the sound transmission loss through an Insulation Glazing Unit (IGU) at frequencies below $500 \mathrm{~Hz}$. To this end, three different configurations based on the experimental conditions described in the standards are used to investigate the acoustic performances of IGU: in the first model, the two rooms are designed; in the two following configurations, either the receiving room or the source room is modeled. Results are compared to those obtained with the ideal free fields conditions in the emitting and receiving sides of the baffled IGU. In this last case, the two reverberant enclosures are removed and perfect fields in the two sides of the structure are considered. In total, the next four configurations are used; 
- IGU mounted between two reverberant rooms (Room-IGU-Room);

- IGU excited by a diffuse sound field (DSF) and coupled to a receiving room (DSF-IGU-Room);

- IGU coupled to the source room and radiates in a free field (Room-IGU-Freefield);

- IGU mounted in an infinite baffle, excited by a diffuse field and radiates in a semi-infinite domain (DSF-IGU-Free-field).

\subsection{Insulating Glazing Unit numerical model}

The numerical model of the Insulating Glazing Unit used to study its vibro-acoustic response is calibrated from Experimental Modal Analysis. This step is essential to take into account all the required details of the structure and its dynamic behavior especially at low frequencies. To this end, the roving hammer approach is employed.

\subsection{Results analysis}

\subsubsection{Theoretical/ Numerical comparison}

First, the results of the sound reduction of a double glazing system calculated with the finite element method are compared with those of an infinite system determined with an analytical approach. Several approaches presented in the literature with the problem of sound transmission through double wall systems, among which, the impedance approach described by Heckl [25] is chosen.

A characteristic phenomenon of the double-partition system is the massair-mass frequency. At this frequency, the two plates move out of phase and the effect of the cavity on the plates is mostly one of added stiffness [26]. This frequency can be calculated approximately by the next expression [25]:

$$
f_{\text {mam }} \cong 1800 \sqrt{\frac{m_{1}+m_{2}}{d m_{1} m_{2}}},
$$

where $d$ is the depth of the acoustic cavity between the panels in $\mathrm{mm}$, and $m_{1}$ and $m_{2}$ are the surface masses of the panels in $\mathrm{kg} / \mathrm{m}^{2}$.

\subsubsection{Comparison of the four numerical configurations}

To investigate the influence of the rooms, the first three configurations are compared to the forth one. Theoretically, Schroeder has shown that the acoustic response of an acoustic enclosure presents two zones: the modal 
region and the high modal density region [10]. The limits between the two zones is known as the "Schroeder frequency $f_{S c h}$ " and depends on the acoustic absorption[10]. For this, inter-comparison of the TL obtained by the four numerical configurations are discussed in two cases: (i) when perfect rigid walls are modeled for the rooms and (ii) when an acoustic absorption is taken into account.

In the first case, the rooms walls are considered perfectly reflecting. In the second case, to better reproduce the test conditions in laboratory, an absorption coefficient $\alpha$ is added to the walls of the rooms expect for the one in which the structure is mounted. It is supposed constant over the surfaces and the frequency range of interest. Its value is deducted from the equivalent sound absorption area $A$ and the absorbing areas of the room $S_{i}$. The values of these two parameters are issued from the data of the experimental tests carried out in CERIBOIS laboratory.

\section{Numerical configurations of the problem}

In this section, the four proposed numerical configurations used to analyze the vibro-acoustic response of the IGU are detailed.

\subsection{Room-IGU-Room}

In the first numerical configuration presented by Fig. 1, the actual laboratory conditions are considered, meaning that both reverberant rooms with rigid walls are modelled. Regarding the excitation side, a monopole source is placed in one of the upper corners of the emitting room in order to excite the maximum number of acoustic modes. The structure is mounted in the common wall in such a way that the left pane of IGU is coupled to the emitting room and the right one is coupled to the receiving one.

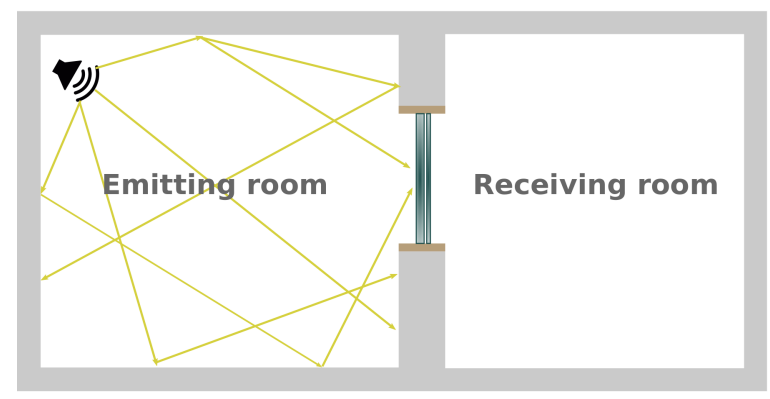

Figure 1: Room-IGU-Room configuration. 
The sound transmission through the structure between the two rooms is calculated by considering the sound field of the source and receiving chambers, the dynamic behavior of the structure and their coupling. A fullycoupled fluid-structure interaction model has been used which means that the vibration of the double-glazing is influenced by the acoustic pressure in the two rooms and these fields are coupled to the structural motion. In the finite element context, this vibro-acoustic problem is described in terms of structural displacement $\mathbf{u}$ and acoustic pressure $p$. The discretization of the variational formulation associated to this problem [27, 28] leads to the following matrix system (see Ref. [26] for details):

$$
\left(\left[\begin{array}{cc}
\mathbf{K}_{u} & -\mathbf{C} \\
\mathbf{0} & \mathbf{K}_{p}
\end{array}\right]-\omega^{2}\left[\begin{array}{cc}
\mathbf{M}_{u} & \mathbf{0} \\
\mathbf{C}^{T} & \mathbf{M}_{p}
\end{array}\right]\right)\left[\begin{array}{l}
\mathbf{U} \\
\mathbf{P}
\end{array}\right]=\left[\begin{array}{l}
\mathbf{F} \\
\mathbf{Q}
\end{array}\right]
$$

where $\mathbf{K}_{u}$ and $\mathbf{M}_{u}$ are the structural stiffness and mass matrices, $\mathbf{K}_{p}$ and $\mathbf{M}_{p}$ are the associated acoustic matrices, $\mathbf{C}$ is the fluid-structure coupling matrix, $\mathbf{F}$ is the nodal force excitation applied on the structure and $\mathbf{Q}$ is the nodal acoustic excitation. The structural and acoustic domains are subdivided into finite elements whose sizes are controlled by the wavelength $\lambda$ which depends on the frequency range of interest. For the fluid domain, we consider the acoustic wavelength defined as $\lambda_{a}=c_{0} / f$ where $c_{0}$ is the sound speed. For the structure, the bending wavelength is $\lambda_{f}=\sqrt{(2 \pi / f)}(D / M)^{1 / 4}$ where $D$ is the bending stiffness and $M$ is the surface mass density. It should be noted that, in order to reduce the computational costs, an incompatible mesh can be used at the structural-acoustic interface by enforcing continuous fields using Lagrange multipliers.

In this model, which is the most complete, the rooms dimension are chosen according to the characteristics of CERIBOIS laboratory. The emitting and receiving rooms dimensions are $5 \times 4.5 \times 3.25 \mathrm{~m}^{3}$ and $5 \times 4 \times 3.25 \mathrm{~m}^{3}$, respectively as shown in Fig. 2.

\section{2. $D S F-I G U-R o o m$}

At low frequencies, to respect the condition of incident diffuse sound field, it is necessary to model a room whose dimensions are much larger than the wavelength, leading to an increase of the computational costs. To overcome this problem, the DSF can be modeled as superposition of an infinite plane waves random in phase, arriving uniformly from all the directions whose propagating vector is pointed toward the structure. In such case: 

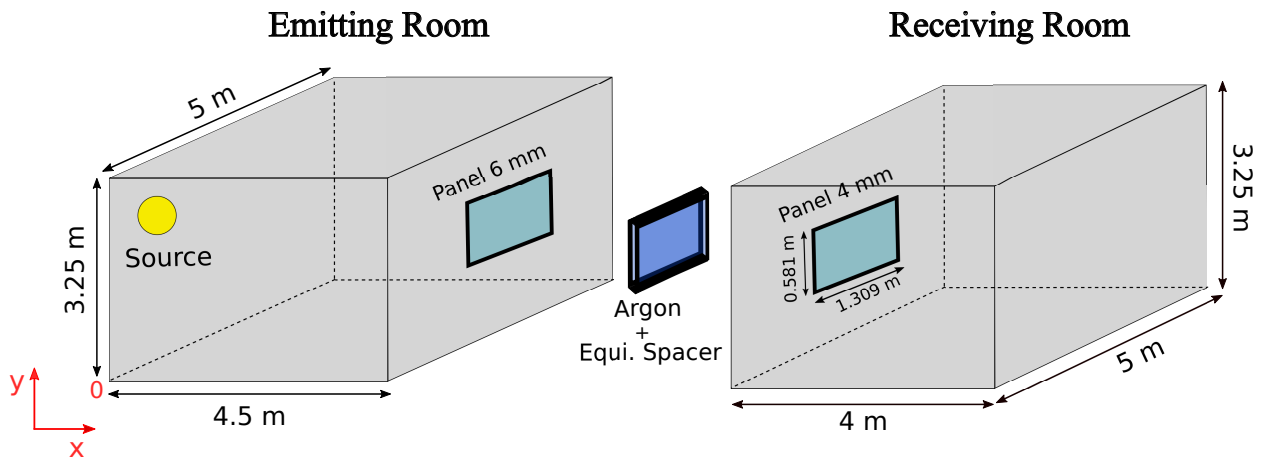

Figure 2: Emitting and receiving rooms connected through the IGU.

$$
\Pi_{i n c}^{d}=\int_{0}^{2 \pi} \int_{0}^{\pi / 2} \Pi_{i n c(\theta, \varphi)} \sin (\theta) d \theta d \varphi
$$

where $\Pi_{i n c(\theta, \varphi)}$ is the incident power of one plane wave calculated as :

$$
\Pi_{i n c(\theta, \varphi)}=\frac{\left|A_{i}\right|^{2} S}{2 \rho_{0} c_{0}} \cos (\theta)
$$

where $A_{i}$ is the complex amplitude of the plane wave defined by the angle along the longitude $\theta$ and the angle according to the colatitude $\varphi, S$ is the area of the plate and $\rho_{0}$ is the mass density of the fluid in the external acoustic domain.

For the receiving side, the clamped structure radiates in a rigid rectangular cavity. In the case of a plane structure, whose radiation surface is coupled to an acoustic enclosure, the radiated power $\Pi_{\text {rad }}$ of the structure in the acoustic domain is given by [29]:

$$
\Pi_{\text {rad }}=\frac{1}{2} \operatorname{Re}\left(\int_{S} p \mathbf{v}_{n}^{*} d S\right)
$$

where $\mathbf{v}_{n}$ is the normal velocity of the structure, $p$ is the wall pressure, * denotes the complex conjugate and $R e$ is the real part of a complex number. The normal velocity $\mathbf{v}_{n}$ is calculated from the finite element formulation (Eq. (4)) applied to the receiving room. The model is illustrated by Fig. 3.

\subsection{Room-IGU-Free-field}

Another interesting configuration consists to eliminate the effect of the receiving room and so to study only the effect of the emitting one. This is approximated by the situation when the receiving side is an anechoic room, 


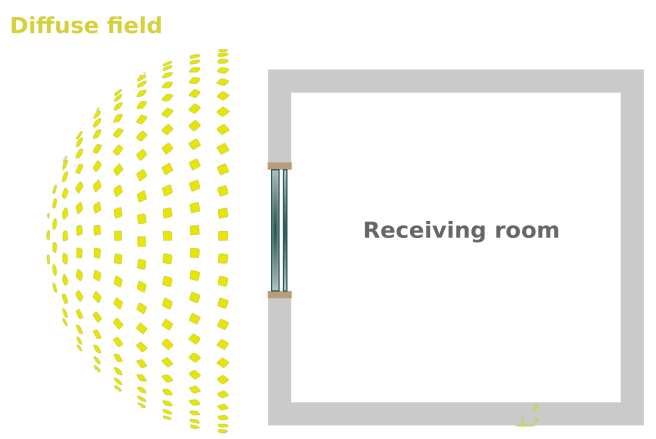

Figure 3: DSF-IGU-Room configuration.

and so, its modal behavior can not be observed. In such a configuration, presented by Fig. 4, the first pane of the double-glazing is coupled to the emitting room and the second one radiates in a half infinite domain.

For a plane vibrating structure mounted on a rigid baffle, the pressure $p$ in the semi-infinite fluid domain can be obtained with the Rayleigh integral [29]. It is defined by:

$$
p(M, \omega)=\frac{i \rho_{0} \omega}{2 \pi} \int_{S} v_{n}(G, \omega) \frac{e^{-i k r}}{r} d S,
$$

where $\rho_{0}$ is the fluid density, $M$ is a point in the semi-infinite acoustic domain, $G$ is a point on the radiating surface $S, v_{n}$ is the normal velocity at the point $G$ defined as $v_{n}=\mathbf{v} . \mathbf{n}$ and $\mathbf{n}$ is the external normal to the structure.

As described by Fahy [6], the baffled vibrating panel can be divided into discrete rectangular elements whose transverse motions are specified in terms of normal velocity at their central position. Assuming that the size $S_{e}$ of the elements is small compared to the acoustic wavelength. The total radiated sound power defined by Eq. $((7))$ can be formulated as the sum of the radiated powers of each element:

$$
\Pi_{\text {rad }}=\frac{S_{e}}{2} \operatorname{Re}\left(\mathbf{v}_{n}^{H} \mathbf{p}\right),
$$

where $H$ is the hermitian transpose, $\mathbf{v}_{n}$ and $\mathbf{p}$ are the vector of complex normal velocity and acoustic pressure in all elements, respectively. In this formulation, the normal velocity vector of each of these elemental sources is related to the vector of sound pressure by the impedance relation:

$$
\mathbf{p}=\mathbf{Z}_{\mathbf{v}_{n}},
$$


where $\mathbf{Z}$ is a symmetric matrix of acoustic impedances. Substituting Eq. ((10)) in the Eq. $((9))$, the total radiated power can be calculated from:

$$
\Pi_{\text {rad }}=\mathbf{v}_{n}^{H} \mathbf{R} \mathbf{v}_{n}
$$

in which $\mathbf{R}$ is the matrix of radiation resistances of the elements dividing the baffled panel and defined as:

$$
\mathbf{R}=\frac{S_{e}^{2} \omega^{2} \rho_{0}}{4 \pi c_{0}}\left[\begin{array}{cccc}
1 & \frac{\sin \left(k r_{12}\right)}{k r_{12}} & \ldots & \frac{\sin \left(k r_{1 R}\right)}{k r_{1 R}} \\
\frac{\sin \left(k r_{21}\right)}{k r_{21}} & 1 & \ldots & \frac{\sin \left(k r_{2 R}\right)}{k r_{2 R}} \\
\vdots & \vdots & \ddots & \vdots \\
\frac{\sin \left(k r_{R 1}\right)}{k r_{R 1}} & \frac{\sin \left(k r_{R 2}\right)}{k r_{R 2}} & \ldots & 1
\end{array}\right]
$$

where $r_{i j}$ is the distance between the centers of the $i^{\text {th }}$ and $j^{\text {th }}$ elements. This method can be applied to any plane structure mounted in an infinite baffle, regardless its boundary conditions.

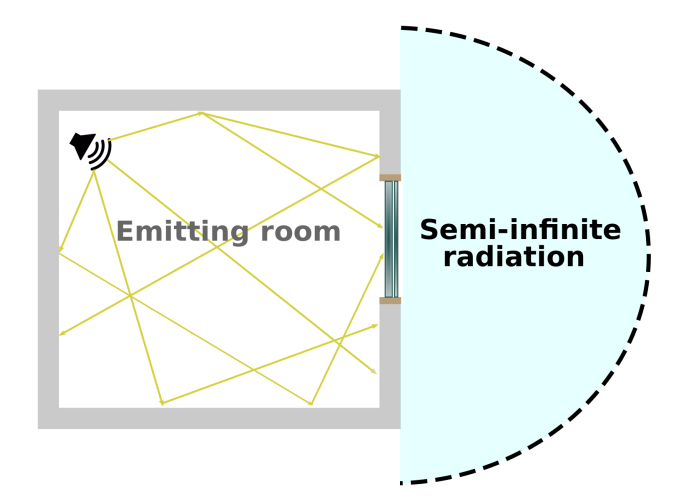

Figure 4: Room-IGU-Free field configuration.

\subsection{DSF-IGU-Free-field}

The fourth configuration showed by Fig. 5 presents the ideal case when the baffled structure is excited by a diffuse field on the emitting side and radiates in a free field in the receiving one. The sound transmission loss is determined from the equations presented in the previous sections. The incident sound power on the first panel is approximated by the summation of the excitation from each individual plane wave (Eq. (6)). In the other side, the radiated sound power from the second panel is given by the formulation in terms of the elemental radiators, Eq. ((11)). 


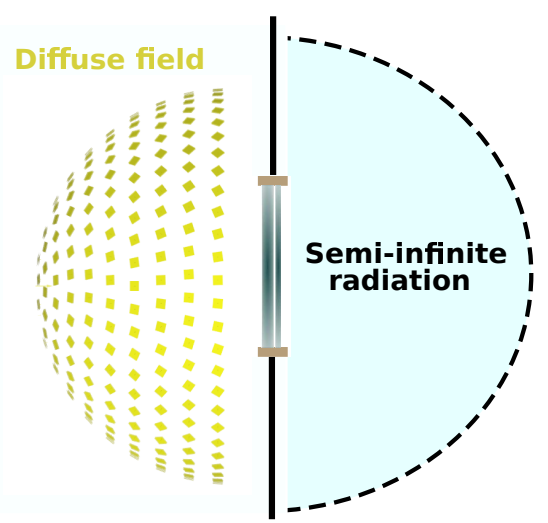

Figure 5: DSF-IGU-free field configuration.

\section{Calibration of the IGU from Experimental Modal Analysis}

As mentioned in the introduction, due to the complexity of the wooden window, the four numerical configurations presented in the previous section will be only applied to the IGU. The latter structure, presented in Fig. 6, consists of two panels of glass separated by an acoustic cavity filled with air or a gaz. In this study, two double glazing systems are considered. The first one, designated by $6 / 18 / 4$, is composed of two panels whose thicknesses are $6 \mathrm{~mm}$ and $4 \mathrm{~mm}$, separated by $18 \mathrm{~mm}$ argon cavity. The second system, designated by $4 / 20 / 4$, is composed of two panels with the same thickness (4 mm), separated by $20 \mathrm{~mm}$ argon cavity.

The panels are linked together along their perimeters by various edge seal systems. It consists of numerous components, including the spacer bar, the desiccant and the sealant. In fact, the stainless hollow steel spacer is half filled at least by the desiccant which is used to dry out the cavity of the IGU. Typically, the desiccants in the IGU are molecular sieves or a mix of silica gel with molecular sieves [30]. The sealant which is a dual combination is commonly used. It is composed of a primary barrier placed between the spacer and the glass panels. For this purpose, a synthetic rubber, typically polyisobutylene (PIB), is usually used. The secondary barrier, which can be silicone, polyurethane or polysulphide [31], is applied around the perimetre of the IGU to join the spacer bar to the glass panels. So, the complexity of the IGU is located along its perimeter. Foret et all [32] tested different edge sealant systems of a nominally IGU and results stated that strong dispersion can be observed for the frequencies below $200 \mathrm{~Hz}$ and notably at the mass-air-mass resonance region. For this reason, the properties of 
the edge seal system of the studied IGU need to be carefully identified. To this end, the Experimental Modal Analysis (EMA) is used to determine the modal parameters of the IGU which are used later to calibrate an equivalent numerical model.

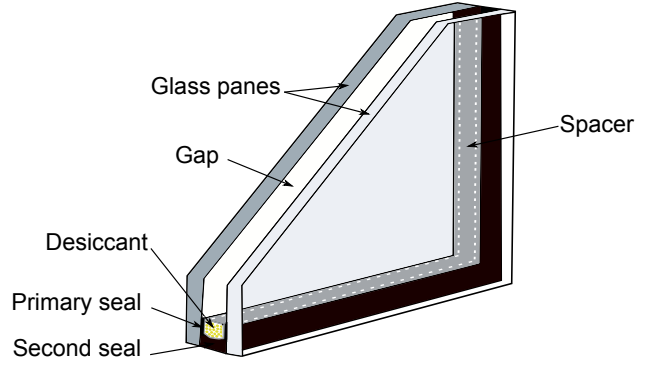

(a)

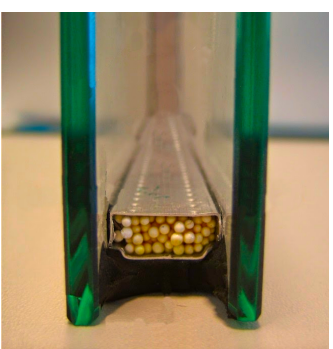

(b)

Figure 6: IGU: (a) Nomenclature and (b) Edge sealant system.

\subsection{Experimental Modal Analysis set-up}

The characterization of the modal parameters of the IGU such as the natural frequencies, the modal shapes and the damping ratios are obtained from an Experimental Modal Analysis (EMA) whose set-up is presented by Fig. 7. The application of this method requires the measurement of the Frequency Response Function (FRF) at different points of the structure after its excitation (Roving Hammer Test). It consists on using the impact hammer which is equipped with a force sensor and a nylon tip to excite the structure. For the response, three reference accelerometers are used to measure the acceleration. The suspended double-glazing (see Fig. 8), of size $0.581 \times 1.309 \mathrm{~m}^{2}$, is composed of two glass panels whose thickness are $6 \mathrm{~mm}$ and $4 \mathrm{~mm}$, separated by $18 \mathrm{~mm}$ of argon. The IGU is meshed into 153 nodes in order to obtain a good visualization of the mode shapes. Excitation is done at all nodes with an average of three impacts and measurements are performed up to $400 \mathrm{~Hz}$ with a frequency resolution of $0.5 \mathrm{~Hz}$.

For performing the EMA, a home-made Matlab toolbox has been developed and includes several approaches like LSCF [33] and its polyreference version [34]. This toolbox consists of several Matlab routines, allowing to establish the complete modal analysis from experimental data step by step. 


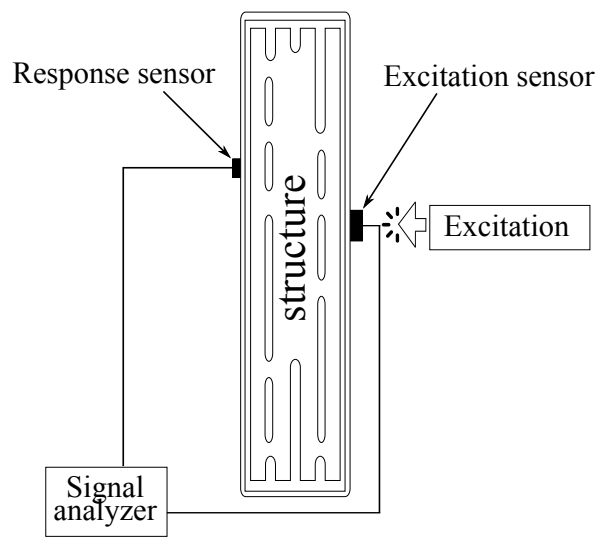

Figure 7: The set-up of Experimental Modal Analysis.

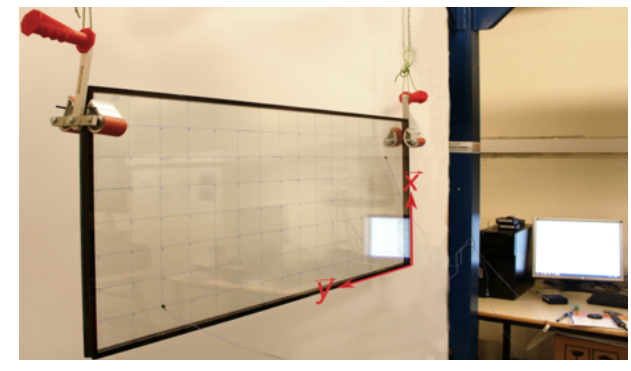

Figure 8: Suspended double-glazing. 
Since the Roving Hammer test is used for this EMA, we must be careful in the quality of tests. Typically, a fairly good and relatively flat Input Power Spectra is required [35]. This recommendation is ensured during the tests as the excitation level presented in Fig. 9 is constant over the whole frequency range. The coherence and the FRF are also used as data quality tools. As we can see from the same figure, the coherence is close to 1 and the quality of the obtained FRF is good with the presence of peaks for all the frequency range.

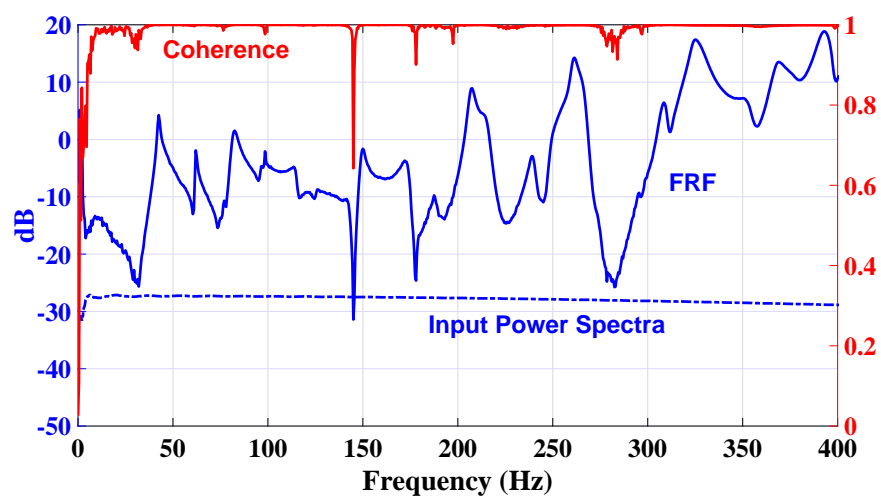

Figure 9: Verification of the quality of the measurement.

In addition, the principle of reciprocity must be verified since the structure is supposed to be linear. It means that the FRF measurements of two points must be the same regardless of which of them is the input or the output. For this, two cases are studied; the first one where the excitation and the measurement points, respectively, P1 and P2, are on the same panel glass. For the second case, the excitation point P1 and the measurement point P2 are in the opposite glasses. The results presented in Fig. 10 show that the system is linear since the curves are superposed following the permutation between the excitation and measurement points, therefore, a linear numerical model can be used for the IGU.

\subsection{Numerical calibrated model}

The IGU experimentally tested is modeled numerically with the finite element method. The objective is to find a numerical representation of the structure able to reproduce its dynamic modal behavior. The numerical model consists of two 2D shells representing the two glass panels separated by a three-dimensional cavity filled with argon (sound speed $c_{0}=317 \mathrm{~m} / \mathrm{s}$ and density $\rho_{0}=1.6 \mathrm{~kg} / \mathrm{m}^{3}$ ). The mechanical properties of the glass are 

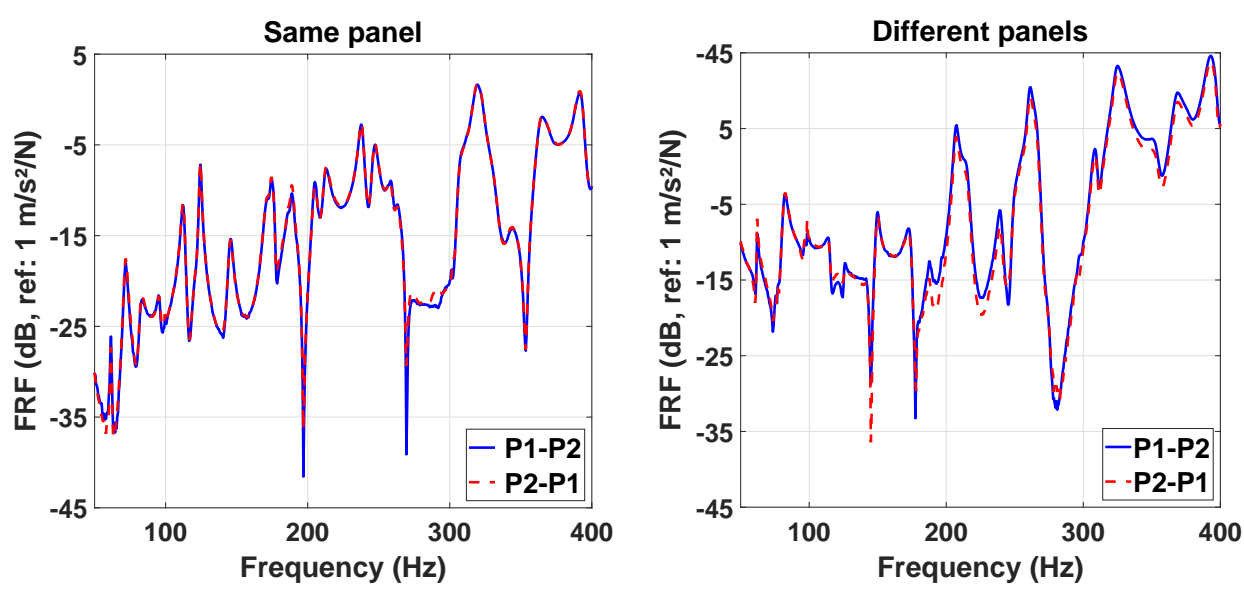

Figure 10: Verification of the system linearity. P1: excitation point- P2: measurement point

$E_{g}=60 \mathrm{GPa} ; \rho_{g}=2450 \mathrm{~kg} / \mathrm{m}^{3}$ and $\nu_{g}=0.23$. For the sealant system, an equivalent sub-domain is defined for the group composed of the spacer, the desiccant and the seal, which is called Equivalent Spacer for the rest of the paper. Its density is calculated from the masses and volumes of its different components. The Table 1 shows the properties of the aluminium for the spacer, Butyl and Silicone of the first and second sealing barrier, respectively. In addition, the indicative mass per linear meter of the desiccant is approximately $62 \mathrm{~g} / \mathrm{m}$. The equivalent density $\rho_{e s}=1523 \mathrm{~kg} / \mathrm{m}^{3}$ is thus obtained. Note that the EMA results will be used for the estimation of the Young Modulus of the Equivalent Spacer.

Table 1: Mechanical properties of the Equivalent Spacer components.

\begin{tabular}{cccc}
\hline \hline Components & Aluminium & Butyl & Silicone \\
\hline$\rho\left(\mathrm{kg} / \mathrm{m}^{3}\right)$ & 2700 & 1200 & 1200 \\
$V\left(\mathrm{~m}^{3}\right)$ & $2,005 \times 10^{-4}$ & $1,323 \times 10^{-5}$ & $2,0412 \times 10^{-4}$ \\
$m(\mathrm{~kg})$ & 0,541 & 0,0159 & 0.245 \\
\hline \hline
\end{tabular}

For the meshing, quadrilateral shell elements for the glass panels and hexahedral elements for the Equivalent Spacer and the fluid are used in the finite element discretization (see Fig. 11). Since it is recommended to use 6 linear elements per acoustic wavelength, and 10 elements for the bending 
wavelength, the final model contains around 35600 degrees of freedom. At the interface between the solid and acoustic domains, structural-acoustic coupling conditions are then enforced. The structure is considered free in the space.

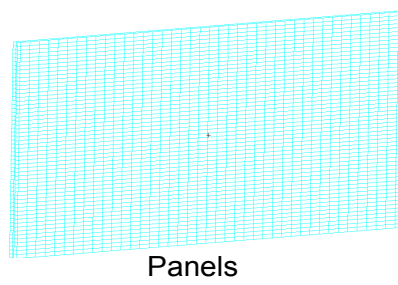

28896 DOFs

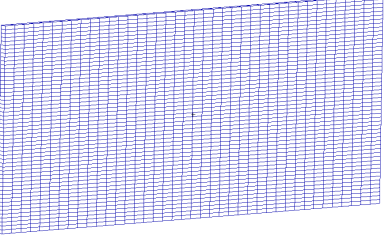

Argon

4427 DOFs

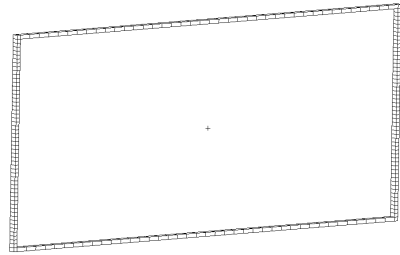

Equivalent Spacer

2277 DOFs

Figure 11: Numerical meshing of the IGU.

\subsection{Results of the model calibration}

The calibration of the model of the Equivalent Spacer is done regarding the first eigenfrequency, but other natural frequencies are presented for the verification. The numerical results presented here are obtained for a Young's modulus of the Equivalent Spacer $E_{e s}=100 \mathrm{MPa}$ and an equivalent Poisson ratio $\nu_{e s}=0.49$. The comparison of the first ten natural frequencies of the structure obtained from the EMA and the numerical analysis of the calibrated model is presented in Fig. 12. The difference of the first natural frequencies is almost zero. For a such complex structure, results are considered satisfying since the maximum difference of results is $6.8 \%$, observed in the $8^{\text {th }}$ mode.

The MAC (Modal Assurance Criterion) is also used out to evaluate the coherence of experimental and numerical modal vectors. The MAC calculated from the comparison of the five first modal shapes is presented in Fig. 13. As it can be seen, the diagonal terms are close to 1 and the offdiagonal terms are less than 0.25 , which means that there is a consistent correspondence between the experimental and numerical results. The corresponding modes shapes are presented in Fig. 14. The first line presents the modal shapes obtained with the EMA and the second line presents the ones found by the FEM of the calibrated model of the IGU.

Regarding the comparison of the eigenfrequencies and the modal shapes, the calibrated numerical model of the IGU is satisying, and therefore, it is used in the next section for the prediction of the sound transmission loss with the four numerical configurations already discussed. 


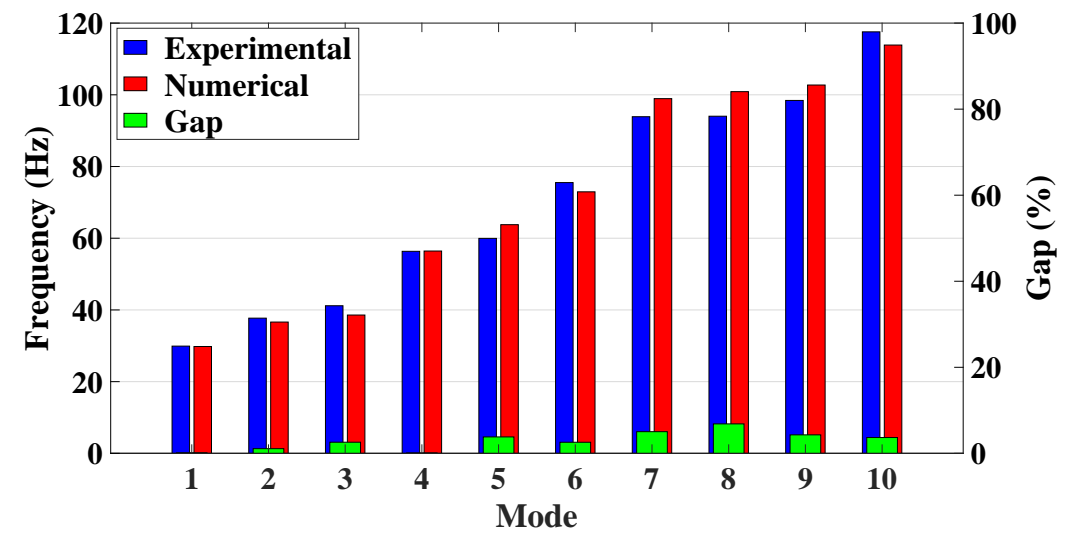

Figure 12: Comparaison of the first ten experimental and numerical eigenfrequencies of the IGU.

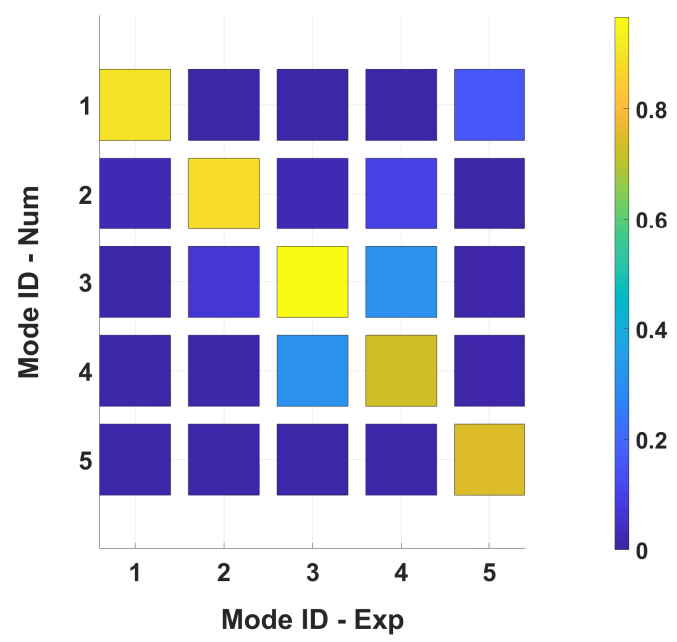

Figure 13: MAC of experimental and numerical mode shapes of the IGU. 


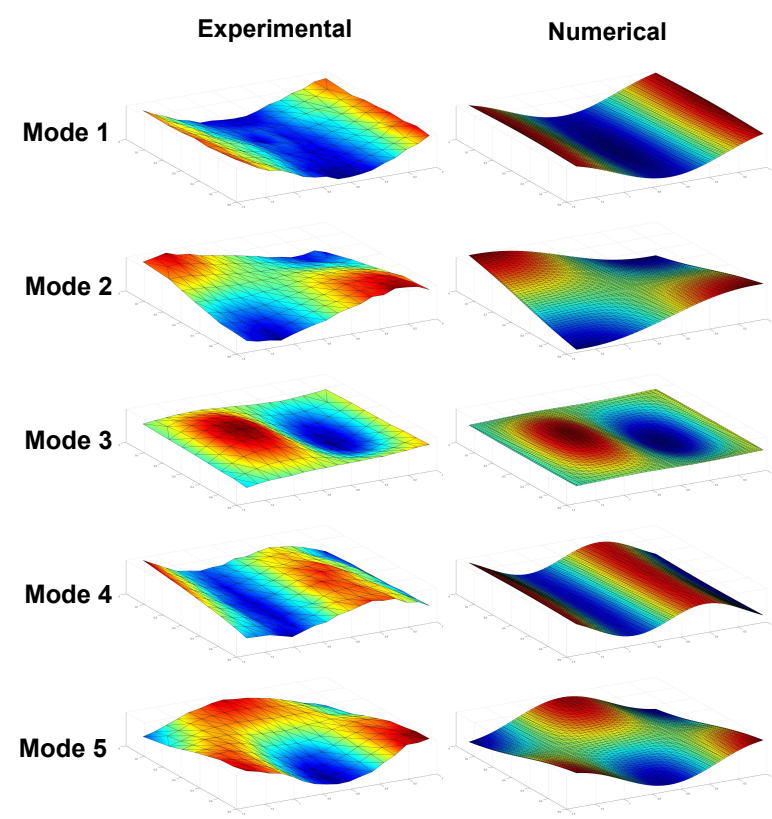

Figure 14: Comparison of the first five experimental and numerical mode shapes of the IGU.

\section{Results of the Transmission Loss}

The analyses have been carried out to investigate the sound transmission loss through the IGU 6/18/4 calibrated in the previous section. To this end, the $6 \mathrm{~mm}$ glass panel is placed in the emitting side and $4 \mathrm{~mm}$ glass panel in the receiving side. A damping coefficient of $1 \%$ is used for all the materials of the structure. The latter is fully clamped at its edges in the common wall of the rooms.

To compare the numerical cost of the four configurations, a comparison of the degrees of freedom (DOF) with considering the size of each model is given in Table 2. With respecting the meshing conditions for the structure and the fluid domains, the first case with the two acoustic rooms has $189 \times 10^{3}$ DOF which is around 5 times the DOF of the case with free field in the both sides of the double glazing.

\subsection{Comparison of the TL of the four configurations}

To study the intrinsic acoustic response of the IGU without any influence of environmental factors, the narrow band transmission loss of the 
Table 2: DOFs of the four configurations.

\begin{tabular}{ccccc}
\hline Configuration & $\mathbf{1}$ & $\mathbf{2}$ & $\mathbf{3}$ & $\mathbf{4}$ \\
\hline DOFs $\left(\times 10^{3}\right)$ & 189 & 110 & 115 & 36 \\
\hline \hline
\end{tabular}

structure predicted with the perfect free-fields configuration is presented in Fig. 15. The result is compared to the one obtained with the impedance approach [25]. As it can be observed, the theoretical TL is higher than the numerical result except in the restricted frequency band around $175 \mathrm{~Hz}$. This has been pointed out by Heckel [25] who stated that the impedance theory can only be applied qualitatively in the case of the double glazing of windows. This was explained by the fact that, in addition to the small size of this type of structure, the argon cavity between the panels has a significant lateral resonances. The mass-air-mass frequency of the studied structure is around $174 \mathrm{~Hz}$ and the corresponding modal shape is illustrated in the Fig. 16. The other dips in the numerical TL (Fig. 15) correspond to the eigenfrequencies of the double glazing whose density increases as the frequency increases.

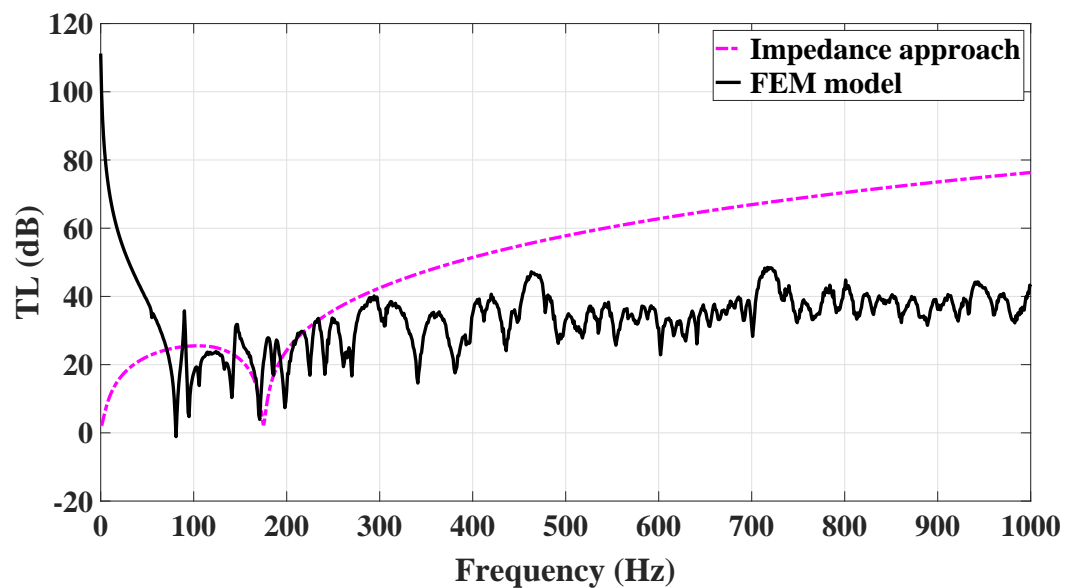

Figure 15: Comparison of the TL between the impedance approach and the FEM $\left(4^{\text {th }}\right.$ configuration).

The coupling of the structure to acoustic rooms change its response and so the transmission of the sound due to two related factors: the first one is the closeness of the eigenfrequencies of the rooms and those of the structure, 


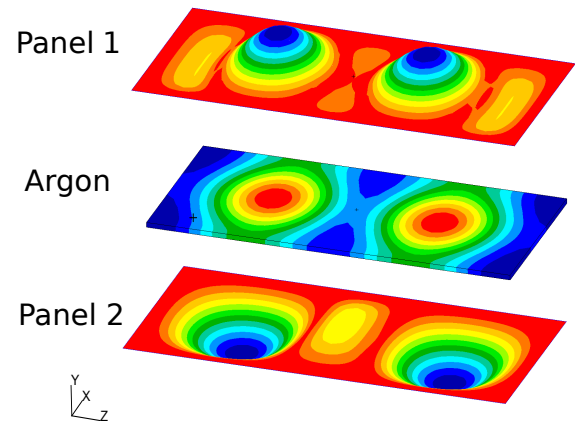

Figure 16: Fluid pressure and panels normal displacement at the mass-air-mass frequency $(174 \mathrm{~Hz})$.

the second is the spatial matching between the distributions of the displacements and the acoustic pressure over the structure [6]. In the first case, a perfect rigid walls are modeled for the rooms. Indeed, even if this case is an extreme situation, this study will highlight the significant effect of the acoustic absorption in the rooms. From the comparison between the four configurations in narrow band presented in Fig. 17a, it can be observed that in very low frequencies, there are visible and separated natural frequencies of the rooms. As a result, intense dips and fluctuations marked the TL in addition to those presenting the modal behavior of the structure. As the frequency increases, this behavior becomes less significant due to the increase of the modal density of the rooms, and so, the TL curves of the configurations with one or two rooms become smoother. From the $1 / 3$-octave spectrum presented in Fig. 17b, it can seen that the results from all the configurations have the same trend for frequencies above $250 \mathrm{~Hz}$, although, a significant difference is observed between them. For example, the difference between the case of the acoustic suit and the perfect free-fields reaches $14.5 \mathrm{~dB}$ in $500 \mathrm{~Hz}$.

In the second case, an absorption coefficient $\alpha$ is added to take into account the acoustic dissipation on the rooms walls. The value of $\alpha$ is averaged from the laboratory's data and a value of about 0.084 is used for the simulation. It gives a Schroeder frequency around $300 \mathrm{~Hz}$. The results of the transmission loss of the IGU calculated when it is mounted on an infinite baffle and other configurations are compared and presented in Fig. 18. For all configurations, comparing to the first case (perfect rigid walls), there is an attenuation and reduction of dips amplitudes and the modal and diffuse 


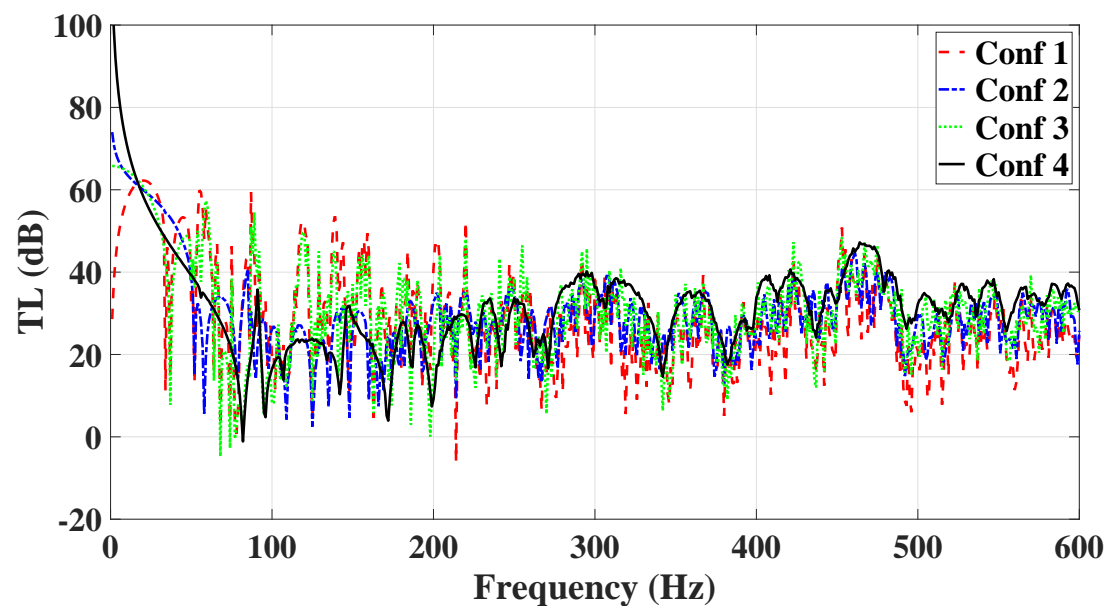

(a) narrow band

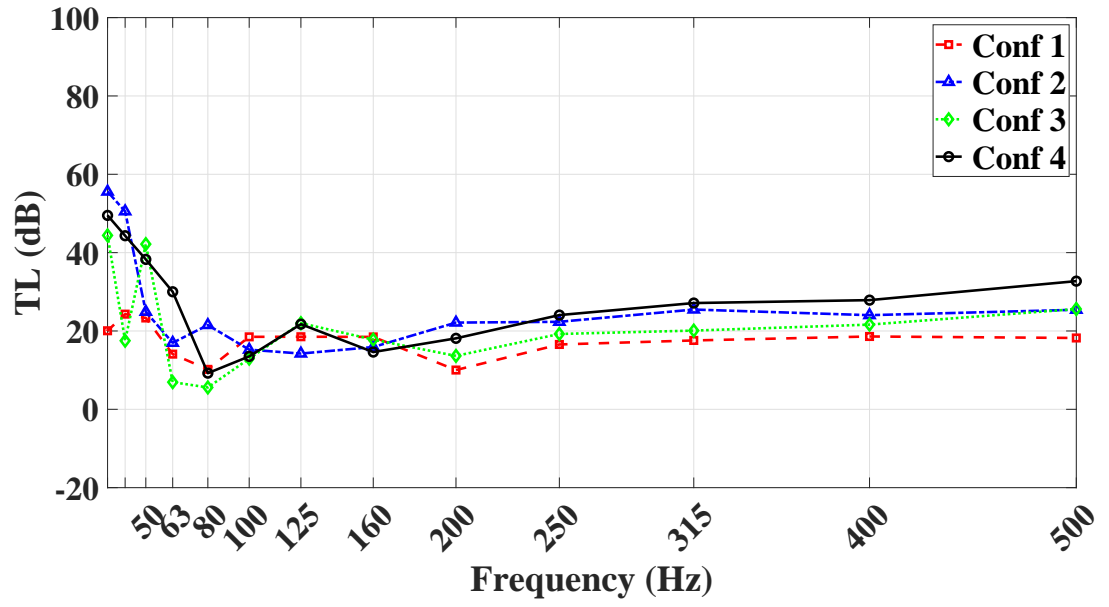

(b) $1 / 3$-octave band

Figure 17: Comparison of TL of the IGU calculated with the four configurations when the rooms walls are perfectly rigid. 
regions are clearly separated (Fig. 18a). The comparison between the TL predicted from the first and the fourth configuration shows that, even with treated walls and absorption coefficient respecting the recommendations of the standards [8], a special care for the measurement of this indicator must be considered in different facilities at low frequencies. From the results of the DSF-IGU-room ( $2^{\text {nd }}$ config) and the perfect free-fields model ( $4^{\text {th }}$ configuration), it can be observed that the modal behavior of the receiving room alone do not significantly affect the transmission loss compared to the ideal case. Finally, the comparison of the case with only the emitting room $\left(3^{\text {rd }}\right.$ configuration) and free-fields configuration shows that the modal behavior of the emitting room is still present at very low frequencies (presented by the dips on the TL curve). So that, the properties of this room dominate the TL calculated with the complete acoustic suite ( $1^{\text {st }}$ configuration). Otherwise, the stationary waves created at the natural frequencies of the source room amplify the mean square pressure in this room. This is can be explained by the sensitivity of the diffuseness of the acoustic field to many parameters such as the source position, the room geometry and the distribution of the absorption in the walls.

A synthesis of the TL calculated with the four configurations in $1 / 3$ octave bands is presented by Fig. 18b. For all the frequency range, TL curves have the same trend with a difference of $4 \mathrm{~dB}$, for example, between the cases with one room $\left(2^{\text {nd }}\right.$ and $3^{\text {rd }}$ config) at $500 \mathrm{~Hz}$. Although, in very low frequencies below $125 \mathrm{~Hz}$, the TL is sensitive to the presence of the source room. To this end, a specific care in the numerical modeling of the room or in the carrying out of the acoustic test in laboratory is recommended in order to avoid its modal behavior and to be closer to the ideal free-fields case.

So in order to extrapolate this survey to other studies with taking into account only the intrinsic properties of the double glazing and not the properties of the rooms, in addition to the computational efficiency compared to the other configurations, the $4^{\text {th }}$ one will be used in the comparison with experimental data of TL.

\subsection{Comparison with experimental measurements}

In order to validate the $4^{\text {th }}$ configuration and the calibrated model of the sealing system of the double glazing, we compare the numerical results with experimental data from the literature. The frequency band depends on the available experimental data. We have chosen to predict the transmission loss 


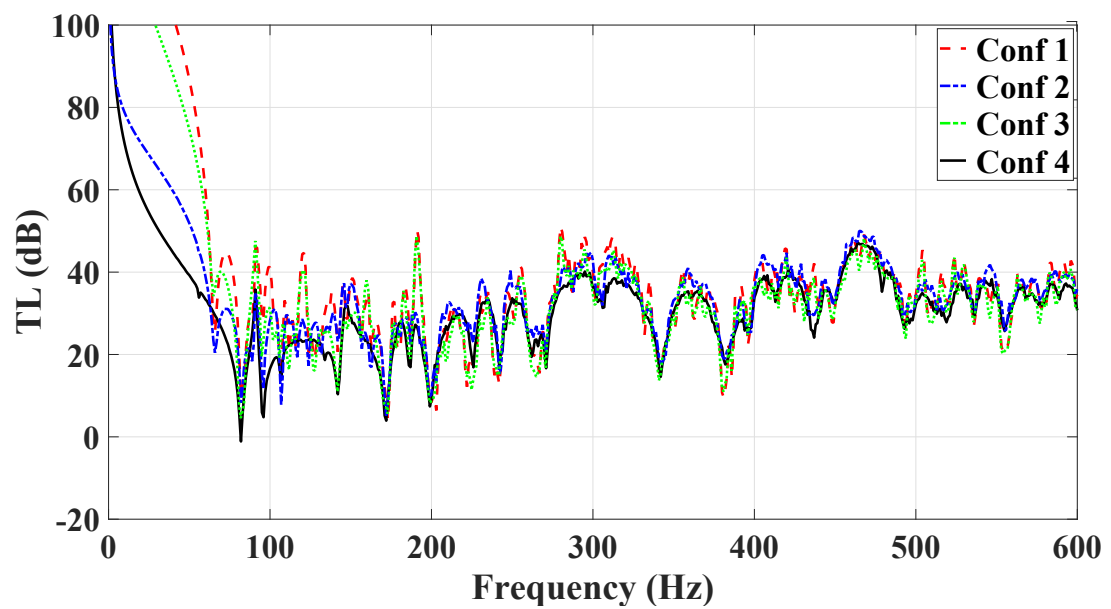

(a) narrow band

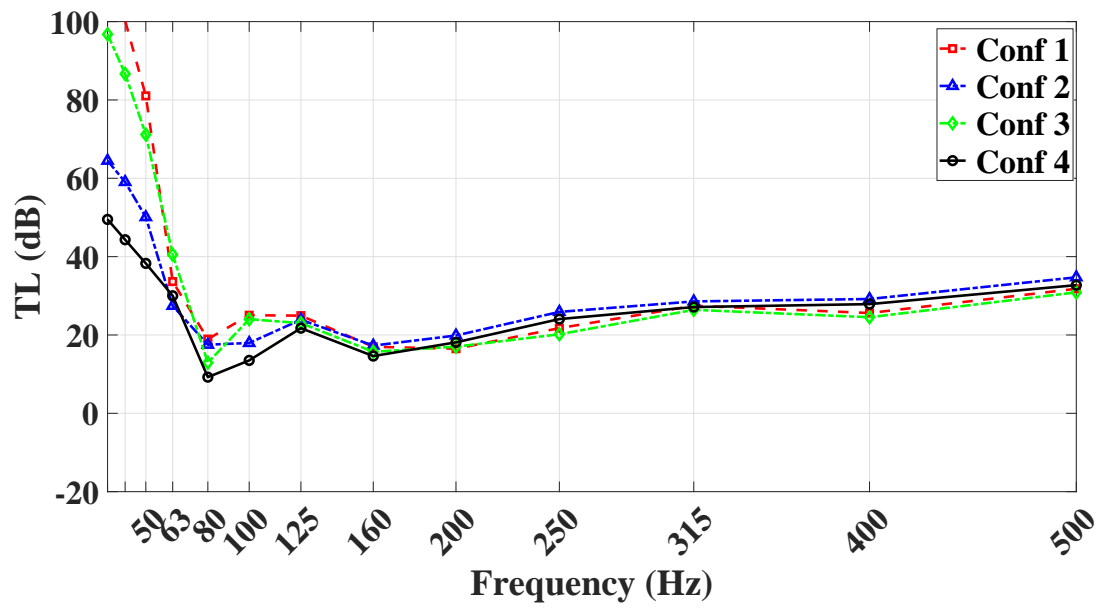

(b) $1 / 3$-octave bands

Figure 18: Comparison of TL of the IGU calculated with the four configurations when the rooms walls are not perfectly rigid. 
of the system up to $500 \mathrm{~Hz}$ when the experimental data starts at $50 \mathrm{~Hz}$, and up to $630 \mathrm{~Hz}$ when measurements are made for frequencies above $100 \mathrm{~Hz}$.

The experimental data presented in this section are derived from measurements made in accordance with the standards [8]. The typical installation of double glazing in the opening of the wall separating the two rooms is shown in Fig. 19. A layer of mineral wool is inserted into the partition of the wall and the wooden opening to reduce the solid sound transmission. After the installation of the double glazing, a compressible foam and a mastic seal are applied to the entire perimeter to eliminate sound leaks. The measurement results are presented in third-octave bands according to the recommendations of the standard [8].

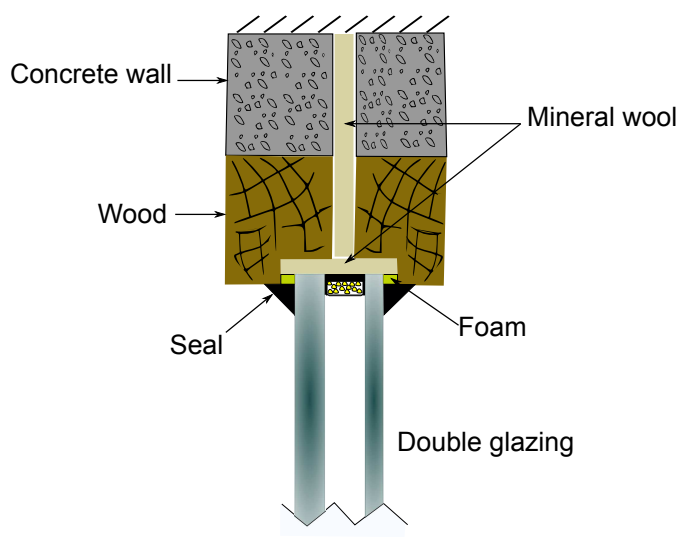

Figure 19: Mounting details of double glazing in the wall for the acoustic test.

For the results issued from Foret et al. [32] work, the type of edge sealant system of the structure is detailed, however, it is unknown for the data issu from the work of Assaf [36]. In fact, the majority of the globally manufactured IGU are dual sealed especially in Europe with about 85-90 \% of commercial glazing units [37]. To this end, the calibrated properties of our model, which is a dual sealed one, are used for the present models.

The results from the work of Foret al. [32] are illustrated in by Fig. 20. In total, seven 4/16/4 IGU have been tested with normalized dimensions which are $1.48 \mathrm{~m}$ wide by $1.23 \mathrm{~m}$ high. The difference between them lies in the sealing system, i.e. the type of the spacer and the two sealing barriers (see Ref. [32] for further details). The Fig. 20a shows the TL of the different configurations tested from $100 \mathrm{~Hz}$ to $630 \mathrm{~Hz}$. Results show that the acoustic performance of the system depends on the sealing system with a difference that can reach about $5 \mathrm{~dB}$ at $200 \mathrm{~Hz}$, corresponding to the resonance region. 
The first IGU that has been tested experimentally has the same sealant system of our model calibrated previously. For that, a comparison of the result of the numerical model and that of the first system is presented in Fig. 20b. A good agreement can be noticed between the two approaches over the whole frequency range with a maximum difference of $1.5 \mathrm{~dB}$ at $315 \mathrm{~Hz}$. In order to asses the validity of our calibrated model, the numerical TL is compared to the average of the seven series of the experimental data (Fig. 20b). It can be seen that the numerical curve falls within the standard deviation from the mean of the experimental results except for the frequencies $125 \mathrm{~Hz}$ and $315 \mathrm{~Hz}$. The degradation of the acoustic performance due to the effect of the resonance mass-air-mass can be clearly distinguished which is estimated at $228 \mathrm{~Hz}$ for the present system.

The second IGU studied is composed of two glass of $6 \mathrm{~mm}$ separated by $12 \mathrm{~mm}$ by a cavity fulled with argon and tested by Assaf [36]. The dimensions of the glass are $1.13 \times 1.38 \mathrm{~m}^{2}$ whose sealing system is not specified. Fig. 21 presents the comparison between numerical and experimental transmission loss. Even with the absence of information (type of the sealent system), the both curves follow the same trend over the frequency range of interest except for the $80 \mathrm{~Hz}$ frequency. For this glazing composition, the analytical mass-air-mass frequency gives a value of $215 \mathrm{~Hz}$ [6], which corresponds to the dip in the TL at $200 \mathrm{~Hz}$ for both results.

The comparison with experimental results of the two double glazing composition show a good agreement with the numerical transmission loss for the whole frequency range even for those below $100 \mathrm{~Hz}$. As a consequence, the calibrated model of the Equivalent Spacer can be considered satisfying acoustically and the $4^{\text {th }}$ configuration leads to predict properly the acoustic performances of the structure independently to the rooms.

\subsection{Parametric analyses}

In this section, the ideal configuration that allows the investigation of the intrinsic characteristics of the IGU is used for parametric survey.

The effect of structural damping on transmission loss is studied here. This parameter, which introduces dissipation into the structure, is important in the analysis of vibrations. To this end, three structural damping coefficients are studied; $0 \%$ (undamped system), $1 \%$ and $2 \%$. Classically, a structural coefficient damping of $1 \%$ is considered. So even if the value $2 \%$ seems unrealistic, it allows to highlight the effect of damping on the 


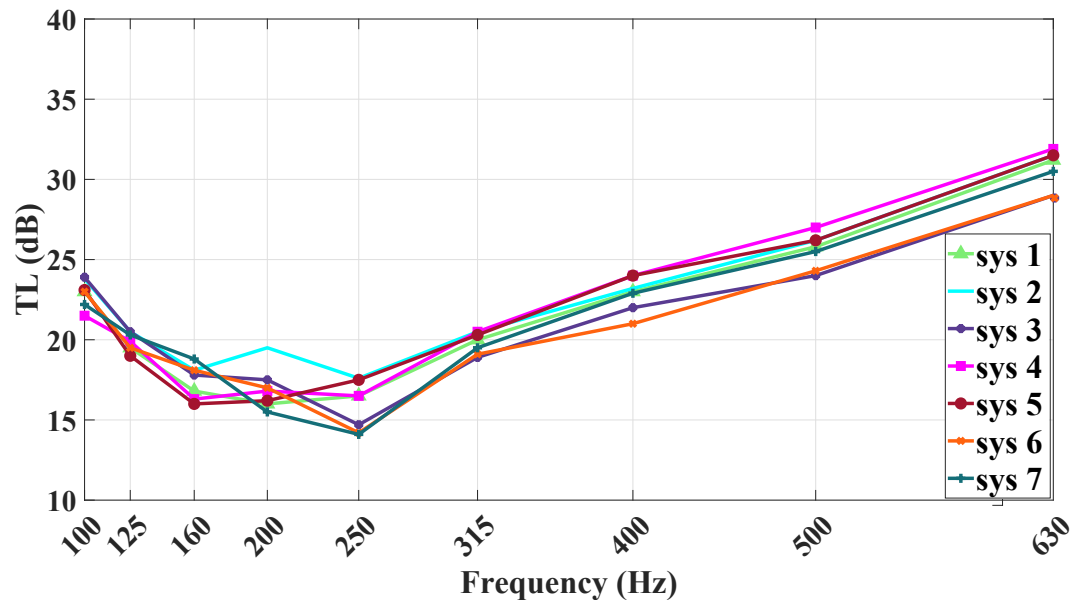

(a) Effect of sealing systems (seven different systems numbered from 1 to 7 - see Ref. [32] for details)

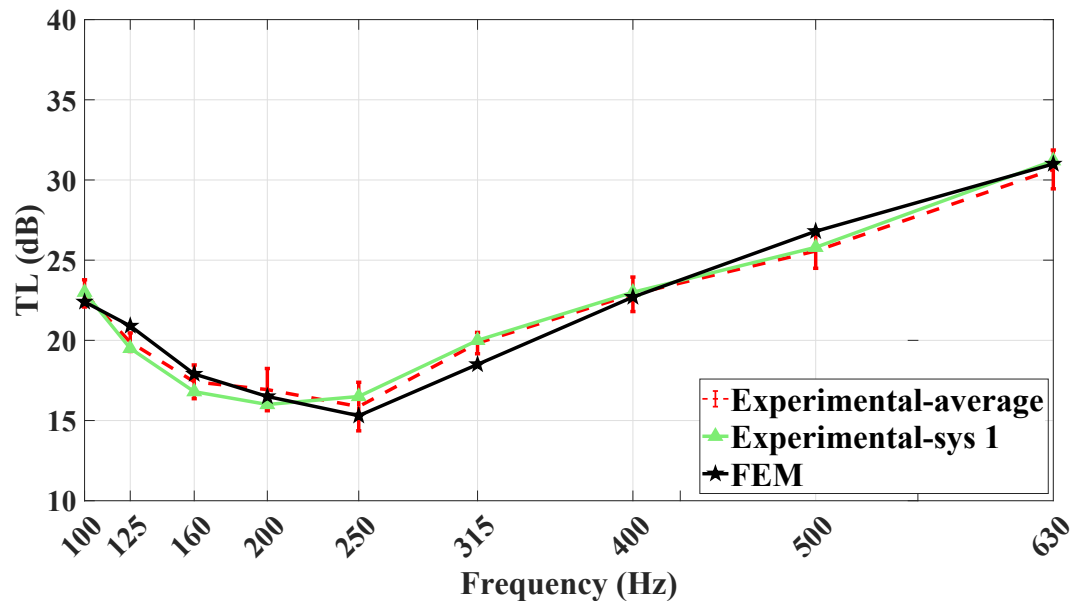

(b) Average of all the experimental (Experimental-average), the experimental of system 1 (Experimental-sys 1) and Numerical(FEM) TL [32]

Figure 20: Comparison of the numerical and experimental transmission loss of a normalized 4/16/4 IGU. 


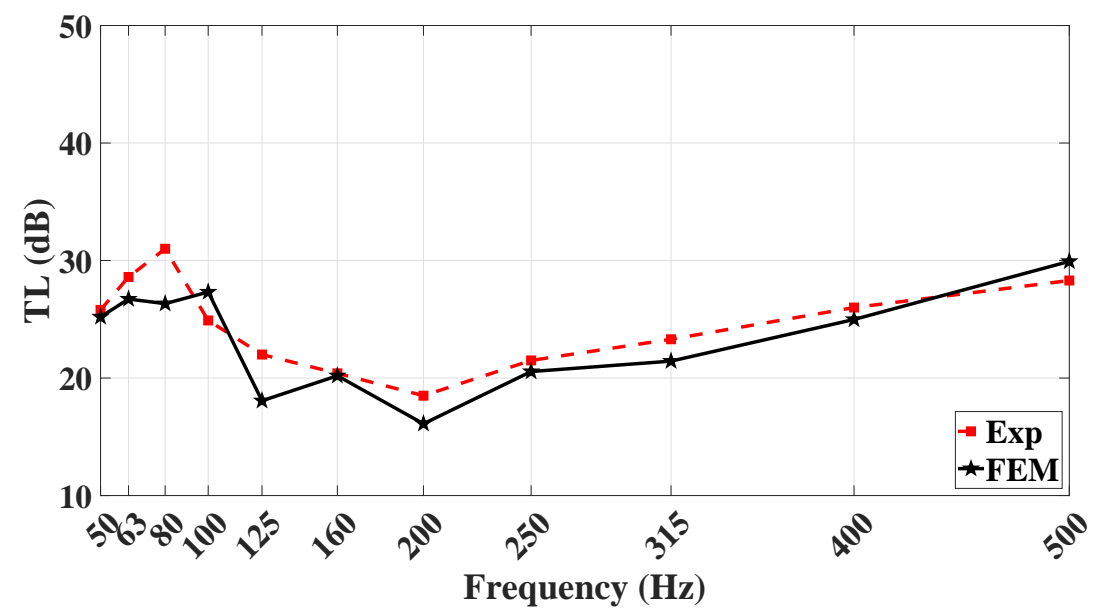

Figure 21: Comparison of the numerical (FEM) and experimental (Exp) TL [36] of 6/12/6 IGU.

evolution of the sound transmission loss. The TL results in the narrow and 1/3-octave band are presented in Fig. 22. From the comparison between both sets of results in narrow band, it can be seen that only around the natural frequencies differences can be observed and hardly influences the overall transmission loss. That explains why the influence of damping increases with the frequency due to the increase in the modal density. These results confirm the known fact that damping has an effect only on the resonances of the structure. The transmission loss below the first eigenfrequency is governed by the stiffness. For the studied structure, the lowest natural frequency is $56 \mathrm{~Hz}$, that is why, it can be observed from the one 1/3-octave band result (Fig. 22b) that the curves are superposed for the center frequencies $40 \mathrm{~Hz}$, $50 \mathrm{~Hz}$ and $63 \mathrm{~Hz}$.

The second parameter considered is the glass thickness. For this purpose, the combination of a $6 \mathrm{~mm}$ glass plate and $18 \mathrm{~mm}$ argon cavity was preserved and the thickness of the second plate was varied from $4 \mathrm{~mm}$ to $10 \mathrm{~mm}$ with a $2 \mathrm{~mm}$ step. Theoretically, in the frequency range of interest, up to $600 \mathrm{~Hz}$, for a such double-partition system, the two regions that can be observed in the TL results are the stiffness and resonance-controlled regions. The results in Fig. 23 show that the modes shift to lower frequencies with the decreasing of the total mass of the system. Below the first resonance frequency, as expected, the sound insulation is governed by the rigidity of the structure. For this, it can be seen that the heaviest structure 6/18/10 


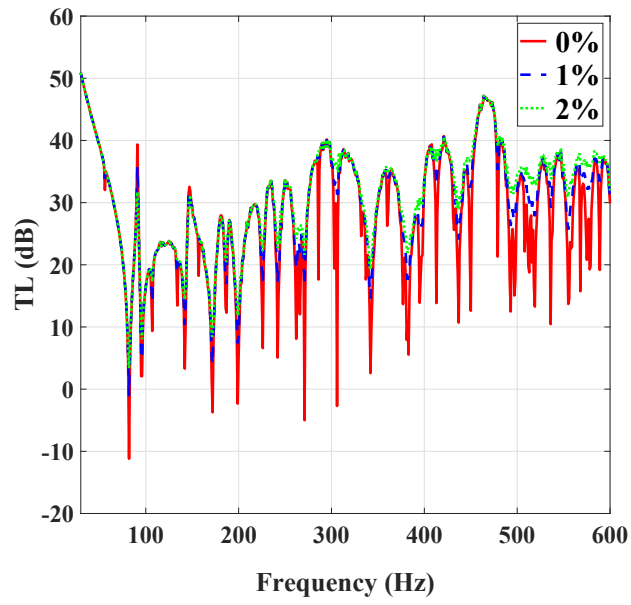

(a) Narrow band

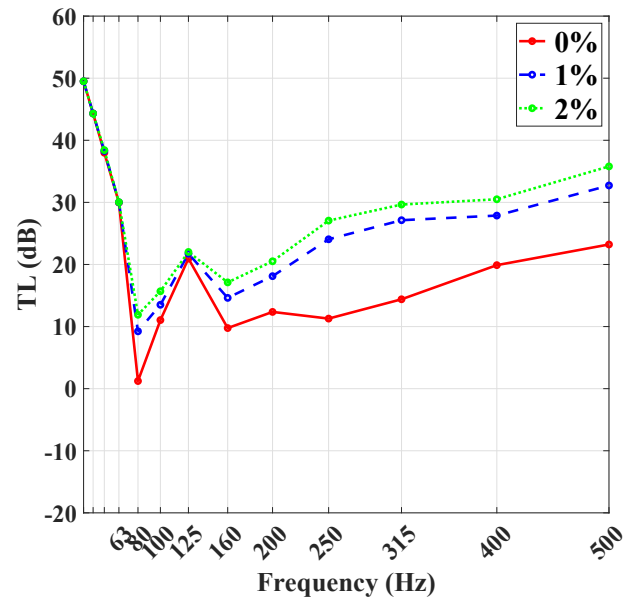

(b) $1 / 3$-octave band

Figure 22: Effect of structural damping on the TL of the IGU.

has the highest TL. Above this frequency there is no clear interpretation due to the influence of the mass-air-mass frequency of each system. For this frequency range, most of the insulation dips at the structural eigenfrequencies of the symmetric double-glazing $6 / 18 / 6$ are greater than those with different glass thickness.

\section{Conclusions}

The sound Transmission Loss (TL) of an Insulating Glazing Unit (IGU) at low frequencies has been studied using the Finite Element Method. In order to study the effect of the rooms on the vibro-acoustic response of the considered structure, four different configurations have been developed that taking into account the acoustic laboratory conditions, either the receiving room or the emitting room and. Finally, the case where the two reverberant rooms are removed and a perfect field is considered in the both side.

The numerical model of the IGU has been calibrated with the Experimental Modal Analysis (EMA). This step was essential to built the numerical model of the structure due to geometrical and mechanical complexities of its edge sealant system components. The criteria used to validate the calibrated numerical model have been satisfied. In fact, the gap between the first numerical and experimental natural frequencies is around $0.3 \%$ and the 


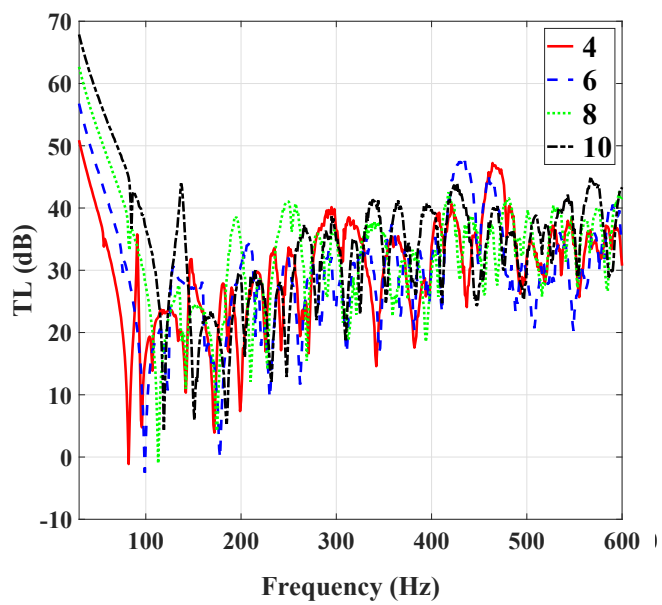

(a) Narrow band

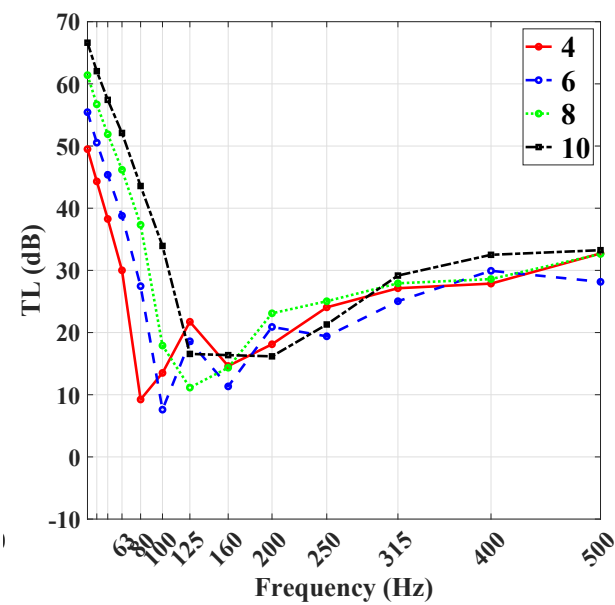

(b) $1 / 3$-octave band

Figure 23: Effect of the panel's thikness on the TL of the IGU.

maximum difference of the first ten frequencies is $6.8 \%$. In addition, the corresponding mode shape show a good agreement with an almost diagonal MAC. The modal damping obtained from the EMA, not discussed here, will be used in future work using the modal approach.

The acoustic analyses pointed out that the results are sensitive to the presence of the rooms due to their modal behavior, especially the emitting one. When the rooms walls are rigid, the difference between the case of the acoustic suit ( $1^{\text {st }}$ configuration) and the perfect free-fields $\left(4^{\text {th }}\right.$ configuration) reaches about $14 \mathrm{~dB}$ in $500 \mathrm{~Hz}$. The add of the acoustic absorption on the rooms walls improves significantly the results especially at low frequencies. In this case, at $500 \mathrm{~Hz}$, the maximum TL difference of $4 \mathrm{~dB}$ is observed between the second ant the third configurations. The $4^{\text {th }}$ configuration that combines free-fields on both sides of the structure ensures a perfect diffuseness of the acoustic field even for the very low frequencies and avoids the modal behavior of the two rooms. Consequently, the problem of the lack of reproducibility will not be faced since this configuration evaluates only the intrinsic performances of the tested element.

In addition, due the computational efficiency of this configuration and in order to extrapolate the study to other IGU models, results issued from this FEM model have been compared to experimental results of different edge 
system models with two glass composition (4/16/4 and 6/12/6). Results showed that the IGU's TL depends on the sealing system and a gap of $5 \mathrm{~dB}$ can be reached between different models at the mass-air-mass resonance region. The comparison of the developed numerical model's results and the experimental ones, when the same edge system is employed, shows a very good agreement for the whole frequency range of interest. A maximum difference of $1.5 \mathrm{~dB}$ was observed at $315 \mathrm{~Hz}$. The same configuration has been used to carry out parametric studies to investigate the influence of the variation of some properties such as the structural damping and the panel's thickness.

Further investigations are conceivable for this work. The immediate application concerns the analysis of the vibro-acoustic response of the full structure i.e. the wooden window with the two opening. Another line of research is the development of reduced order models to optimize the numerical calculation cost. Finally, extension of future window's model to other types of elements of construction could be considered, in particular wood window doors.

\section{Acknowledgements}

The authors would like to express their thanks to CODIFAB (Comité professionnel de développement des industries françaises de l'ameublement et du bois) for its financial support.

\section{References}

[1] J. Mathys. Low-frequency noise and acoustical standards. Appl. Acoust., 40(3):185-199, 1993.

[2] L. L. Beranek and G. A. Work. Sound Transmission through Multiple Structures Containing Flexible Blankets. J. Acoust. Soc. Am., 21(4):419-428, 1949.

[3] A. London. Transmission of reverberant sound through double walls. J. Acoust. Soc. Am., 22(2):270-279, 1950.

[4] A. J. Price and M. J. Crocker. Sound transmission through double panels using statistical energy analysis. J. Acoust. Soc. Am., 47(3A):683693, 1970. 
[5] B. H. Sharp. A study of techniques to increase the sound insulation of building elements. Technical, Wyle laboratories report WR73-5, El Segundo, California, USA (Prepared for Department of Housing and Urban Development HUD, Washington, USA), 1973.

[6] F. Fahy. Sound and structural vibration: radiation, transmission, and response. Academic Press, London ; Orlando, 1985.

[7] V. Hongisto. Sound insulation of double panels - Comparison of existing prediction models. Acta Acust. united with Acust., pages 61-78, 2006.

[8] ISO 10140 : Acoustics - laboratory measurement of sound insulation of building elements: Part 1: Application rules for specific products; Part 2: Measurement of airborne sound insulation; Part 4: Measurement procedures and requirements; Part 5: Requirements for test facilities and equipment, 2010.

[9] H. Nélisse and J.Nicolas. Characterization of a diffuse field in a reverberant room. J. Acoust. Soc. Am., 101(6):3517-3524, 1997.

[10] M. R. Schroeder. The "Schroeder frequency" revisited. J. Acoust. Soc. Am., 99(5):3240-3241, 1996.

[11] W. A. Utley. Single leaf transmission loss at low frequencies. J. Sound Vib., 8(2):256-261, 1968.

[12] T. Kihlman and A. C. Nilsson. The effects of some laboratory designs and mounting conditions on reduction index measurements. J. Sound Vib., 3(24):349-364, 1972.

[13] R. E. Jones. Intercomparisons of laboratory determinations of airborne sound transmission loss. J. Acoust. Soc. Am., 66(1):148-164, 1979.

[14] D. B. Pederson, J. Roland, G. Raabe, and W. Maysenhölder. Measurement of the low-frequency sound insulation of building components. Acta Acust. united with Acust., pages 495-505, 2000.

[15] A. Prato and A. Schiavi. Sound Insulation of Building Elements at Low Frequency: A Modal Approach. Energy Proced., 78:128-133, 2015.

[16] E. E. Unger. Statistical Energy Analysis of vibrating systems. J. Eng. Ind. Trans. Am. Soc. Mech. Eng., pages 629-632, 1967.

[17] R. H. Lyon. Statistical Energy Analysis of Dynamical Systems. Theory and Application. MIT Press, 1975. 
[18] L. Maxit and J.-L. Guyader. Statistical modal energy distribution analysis(smeda). In Proceedings of Sixth International Congress on Sound and vibration, Copenhagen, Denmark, 1999.

[19] A. Tadeu and J. M . P. António. Acoustic insulation of single panel walls provided by analytical expressions versus the mass law. J. Sound Vib., 257(3):457-475, 2002.

[20] P. J. Shorter and R. S. Langley. Vibro-acoustic analysis of complex systems. J. Sound Vib., 288(3):669-699, 2005.

[21] P. Santos and A. Tadeu. Acoustic insulation provided by a single wall separating two contiguous tunnels via BEM. J. Sound Vib., 257(5):945965, 2002.

[22] F. C. Sgard, N. Atalla, and J. Nicolas. A numerical model for the low frequency diffuse field sound transmission loss of double-wall sound barriers with elastic porous linings. J. Acoust. Soc. Am., 108(6):28652872,2000 .

[23] S. P. S. Maluski and B. M. Gibbs. Application of a finite-element model to low-frequency sound insulation in dwellings. J. Acoust. Soc. Am., 108(4):1741-1751, 2000.

[24] ISO 12999-1 : Acoustics - Determination and application of measurement uncertainties in building acoustics - Part 1: Sound insulation, 2014 .

[25] M. Heckl. The tenth sir richard fariry memorial lecture: sound transmission in buildings. J. Sound Vib., pages 165-189, 1981.

[26] W. Larbi, J.-F. Deü, and R. Ohayon. Vibroacoustic analysis of doublewall sandwich panels with viscoelastic core. Comput. Struct., 174:92103, 2016.

[27] W. Larbi, J-F. Deü R., and Ohayon. A new finite element formulation for internal acoustic problems with dissipative walls. International Journal for Numerical Méthods in Engineering, 68(3):381-399, 2006.

[28] W. Larbi, J-F. Deü, and R. Ohayon. Vibration of axisymmetric composite piezoelectric shells coupled with internal fluid. International Journal for Numerical Methods in Engineering, 71(12):1412-1435, 2007. 
[29] A. D. Pierce. Acoustics: An Introduction to Its Physical Principles and Applications. Springer International Publishing, New York, 3rd edition, 1981.

[30] S. L. Meisel. Role of desiccants, complex subject made easy. Glass Magazine, pages 98-102, 2005.

[31] T. Wolf and L. J. Waters. Factors governing the life expectancy of dual-sealed insulating glass units. Constr. Build. Mater., 7 (2):101-107, 1993.

[32] R. Foret, C. Guigou-Carter, P. Jean, and J.-B. Chéné. Effect of spacer designs on acoustic performance of windows. In Proceedings of $E U$ RONOISE, the International Modal Analysis Conference, Edinburgh, Scotland, 2009.

[33] P. Guillaume, P. Verboven, and S. Vanlanduit. A poly-reference implementation of the least-squares complex frequency-domain estimator. In Proceedings of IMAC 21, the International Modal Analysis Conference, Kissimmee, Florida, USA, 2003.

[34] M. El-Kafafy, B. Peeters, T. De Troyer, and P. Guillaume. Polymax Plus estimator: better estimation of the modal parameters and their confidence bounds. In Proceedings of International Noise and Vibration conference ISMA 2014, Leuven, Belgium, 2014.

[35] P. Avitabile. Modal testing : A practitioner's guide. Wiley, 1st edition, 2017.

[36] R. Assaf. Analyse du comportement vibroacoustique des parois multicouches composites dans les constructions. PhD thesis, Conservatoire national des arts et metiers, 2015.

[37] A. T. Wolf. Silicone sealed insulating glass units. In International symposium on the Application of Architectural Glass (ISAAG), 2004. 